\title{
Interhospital competition and hospital charges and costs for patients undergoing cranial neurosurgery
}

\author{
*Oliver Y. Tang, BS, ${ }^{1}$ Krissia M. Rivera Perla, BS, ${ }^{1}$ Rachel K. Lim, ${ }^{1}$ James S. Yoon, BS, ${ }^{2}$ \\ Robert J. Weil, MD, MBA, ${ }^{3}$ and Steven A. Toms, MD, MPH ${ }^{1,3}$ \\ ${ }^{1}$ The Warren Alpert Medical School of Brown University, Providence, Rhode Island; ${ }^{2}$ Yale School of Medicine, New Haven, \\ Connecticut; and ${ }^{3}$ Department of Neurosurgery, Rhode Island Hospital, Providence, Rhode Island
}

\begin{abstract}
OBJECTIVE Research has documented significant growth in neurosurgical expenditures and practice consolidation. The authors evaluated the relationship between interhospital competition and inpatient charges or costs in patients undergoing cranial neurosurgery.

METHODS The authors identified all admissions in 2006 and 2009 from the National Inpatient Sample. Admissions were classified into 5 subspecialties: cerebrovascular, tumor, CSF diversion, neurotrauma, or functional. Hospitalspecific interhospital competition levels were quantified using the Herfindahl-Hirschman Index (HHI), an economic metric ranging continuously from 0 (significant competition) to 1 (monopoly). Inpatient charges (hospital billing) were multiplied with reported cost-to-charge ratios to calculate costs (actual resource use). Multivariate regressions were used to assess the association between $\mathrm{HHI}$ and inpatient charges or costs separately, controlling for 17 patient, hospital, severity, and economic factors. The reported $\beta$-coefficients reflect percentage changes in charges or costs (e.g., $\beta$-coefficient $=1.06$ denotes a $+6 \%$ change). All results correspond to a standardized -0.1 change in $\mathrm{HHI}$ (increase in competition).
\end{abstract}

RESULTS In total, 472,938 nationwide admissions for cranial neurosurgery treated at 896 unique hospitals met inclusion criteria. Hospital HHIs ranged from 0.099 to 0.724 (mean $0.298 \pm 0.105$ ). Hospitals in more competitive markets had greater charge/cost markups $(\beta$-coefficient $=1.10, p<0.001)$ and area wage indices $(\beta$-coefficient $=1.04, p<0.001)$. Between 2006 and 2009, average neurosurgical charges and costs rose significantly $(\$ 62,098$ to $\$ 77,812, p<0.001$; $\$ 21,385$ to $\$ 22,389, p<0.001$, respectively). Increased interhospital competition was associated with greater charges for all admissions ( $\beta$-coefficient $=1.07, p<0.001$ ) as well as cerebrovascular ( $\beta$-coefficient $=1.08, p<0.001$ ), tumor $(\beta$-coefficient $=1.05, p=0.039)$, CSF diversion ( $\beta$-coefficient $=1.08, p<0.001)$, neurotrauma $(\beta$-coefficient $=1.07, p<$ 0.001 ), and functional neurosurgery ( $\beta$-coefficient $=1.11, p=0.037$ ) admissions. However, no significant associations were observed between $\mathrm{HHI}$ and costs, except for CSF diversion surgery ( $\beta$-coefficient $=1.03, p=0.021$ ). Increased competition was not associated with important clinical outcomes, such as inpatient mortality, favorable discharge disposition, or complication rates, except for lower mortality for brain tumors ( $O R=.78, p=0.026$ ), but was related to greater length of stay for all admissions ( $\beta$-coefficient $=1.06, p<0.001$ ). For a sensitivity analysis adjusting for outcomes, all findings for charges and costs remained the same.

CONCLUSIONS Hospitals in more competitive markets exhibited higher charges for admissions of patients undergoing an in-hospital cranial procedure. Despite this, interhospital competition was not associated with increased inpatient costs except for CSF diversion surgery. There was no corresponding improvement in outcomes with increased competition, with the exception of a potential survival benefit for brain tumor surgery.

https://thejns.org/doi/abs/10.3171/2020.6.JNS20732

KEYWORDS Herfindahl-Hirschman Index; HHI; healthcare economics; healthcare costs; health policy; perioperative outcomes; National Inpatient Sample; NIS

ABBREVIATIONS ACA = Patient Protection and Affordable Care Act; APR-DRG = All Patient Refined DRG; CMS = Centers for Medicare and Medicaid Services; DRG = Diagnosis-Related Group; HCUP = Healthcare Cost and Utilization Project; HHI = Herfindahl-Hirschman Index; LOS = length of stay; LOWESS = locally weighted scatterplot smoothing; NIS = National Inpatient Sample.

SUBMITTED March 10, 2020. ACCEPTED June 1, 2020.

INCLUDE WHEN CITING Published online October 2, 2020; DOI: 10.3171/2020.6.JNS20732.

${ }^{*}$ R.J.W. and S.A.T. contributed equally to this work. 
$\mathrm{R}$ ISING expenditures pose a significant challenge in American healthcare, including neurosurgery. Neurosurgery is expensive, with average inpatient costs per admission increasing nearly $60 \%$, from $\$ 15,716$ to $\$ 24,754$, over a 13 -year span. ${ }^{1}$ Some of this growth in cost may be passed on to patients. One single-institution study documented a nearly $\$ 700$ increase in mean patient out-of-pocket private insurance spending from 2013 to $2016 .{ }^{2}$ With $35 \%$ of US adults reporting medical access limitations, including delaying care, due to rising costs, the sharp growth in neurosurgical expenditures has implications for patient access and outcomes. ${ }^{3}$

Interhospital competition is one factor to consider in expense growth. While increased competition is traditionally conceived by economists as a spur to improve customer service, lower prices, or both, this has not always proven true in healthcare. ${ }^{4-6}$ Although some studies suggest that prices rise in more consolidated markets through enhanced bargaining power, ${ }^{7,8}$ others assert that in more competitive markets, hospitals and integrated systems raise prices by driving a "medical arms race" where institutions adopt expensive technologies. ${ }^{9,10}$ Additionally, interhospital competitive intensity may differentially impact hospital charges (the amount that the institution bills) and hospital costs (the actual expenses incurred during admission for labor, supplies, and services). For general surgery, Chang et al. demonstrated that while increased interhospital competition predicted elevated hospital charges, competition was not associated with costs. ${ }^{11}$ Similarly, Durand et al. demonstrated that elevated competition is also associated with increased charges in the setting of lumbar fusion. ${ }^{9}$

However, the relationship between interhospital competition and neurosurgical inpatient expenditures remains poorly understood for cranial neurosurgery. We examined whether interhospital competition, as defined by the Herfindahl-Hirschman Index (HHI), alters inpatient charges and costs for a nationwide population of cranial neurosurgery patients.

\section{Methods}

\section{Data Source}

\section{National Inpatient Sample}

In the years 2006 and 2009, we analyzed inpatient admissions in the National Inpatient Sample (NIS), the largest all-payer inpatient database in the US. ${ }^{12}$ For each year, the NIS, developed as part of the Healthcare Cost and Utilization Project (HCUP), sampled a unique 20\% cohort of the approximately 5000 US nonfederal hospitals and included data on all inpatient discharges from these institutions. As a result, data on all admissions treated at 1840 hospitals in 2006 and 2009 were initially screened for cranial neurosurgery procedures. The NIS contains survey weights to make national estimates from this $20 \%$ hospital sample.

In 2006 and 2009, we identified all inpatient admissions during which an individual underwent a cranial neurosurgery procedure. Due to the lack of service line data in the NIS, we used previously validated national assessments of neurosurgery and selected all patients clas- sified to 1 of 11 surgical Diagnosis-Related Group (DRG) codes corresponding to cranial neurosurgery procedures (Supplementary Table 1). ${ }^{1,13}$ Admissions were categorized into 5 mutually exclusive subspecialties using the ICD-9 codes for diagnosis and primary procedure: cerebrovascular ${ }^{14}$ tumor, ${ }^{15} \mathrm{CSF}$ diversion, ${ }^{16}$ neurotrauma,${ }^{17}$ or functional. ${ }^{18,19}$ Approximately one-third of admissions did not have sufficient coding data for classification and were only included in the overall analysis. Due to the prevalence of missing race data $(>25 \%)$, missing data on race was imputed using multinomial logistic regression with age, sex, insurance, residential income, and census region, following HCUP's statistical recommendations. ${ }^{20}$ Patients with remaining missing data for variables in our multivariate models $(<8 \%)$ were excluded from multivariate analysis (Fig. 1). This study was exempt from institutional review board approval due to the de-identified and public nature of the NIS.

\section{Herfindahl-Hirschman Index}

The 2006 and 2009 NIS datasets were selected for the purposes of this study because they include supplementary Hospital Market Structure files containing data on the HHI, a validated economic metric for quantifying market competition between hospitals, as commonly applied in areas like antitrust law..$^{21}$ The HHI for a given hospital market equals the sum of squared discharge shares for each hospital in the market. For example, a market of 4 hospitals equally sharing discharges would have an $\mathrm{HHI}$ equal to $0.25\left(\mathrm{HHI}=0.25^{2}+0.25^{2}+0.25^{2}+0.25^{2}\right)$. HHI ranges continuously from 0 (significant competition) to 1 (monopoly). Hospital market borders were defined using a patient-flow approach whereby each hospital's market is composed of ZIP codes accounting for $95 \%$ of that institution's discharges. ${ }^{10,12}$ This method accounts for geographic variability in individual hospital patient populations, especially for care as specialized as neurosurgery. HHI scores were calculated using all US nonfederal hospitals, including nonsampled institutions, and all individual hospitals were considered competitors, regardless of ownership by a larger system. We assessed the HHI for hospital of admission as the primary independent variable.

\section{Neurosurgical Expenditures}

Inpatient charges and costs were analyzed separately as outcomes. Data on charges are included as a native variable in the NIS. Costs were calculated by multiplying charges with hospital-specific, cost-to-charge ratios provided by the Centers for Medicare and Medicaid Services (CMS). ${ }^{22}$ For each hospital, this unique cost-to-charge ratio is calculated using hospital accounting reports containing data on all-payer inpatient costs and corresponding charges for all patients. We reported the reciprocal of each hospital's cost-to-charge ratio as its "charge/cost markup" (ratio of charges over costs). Charges and costs were adjusted for inflation to 2009 US dollars using the Consumer Price Index. HCUP provides data on each hospital's area wage index, which reflects geographic variation in hospital wage levels for a hospital's location compared to the national average, with a greater wage index signifying more expen- 


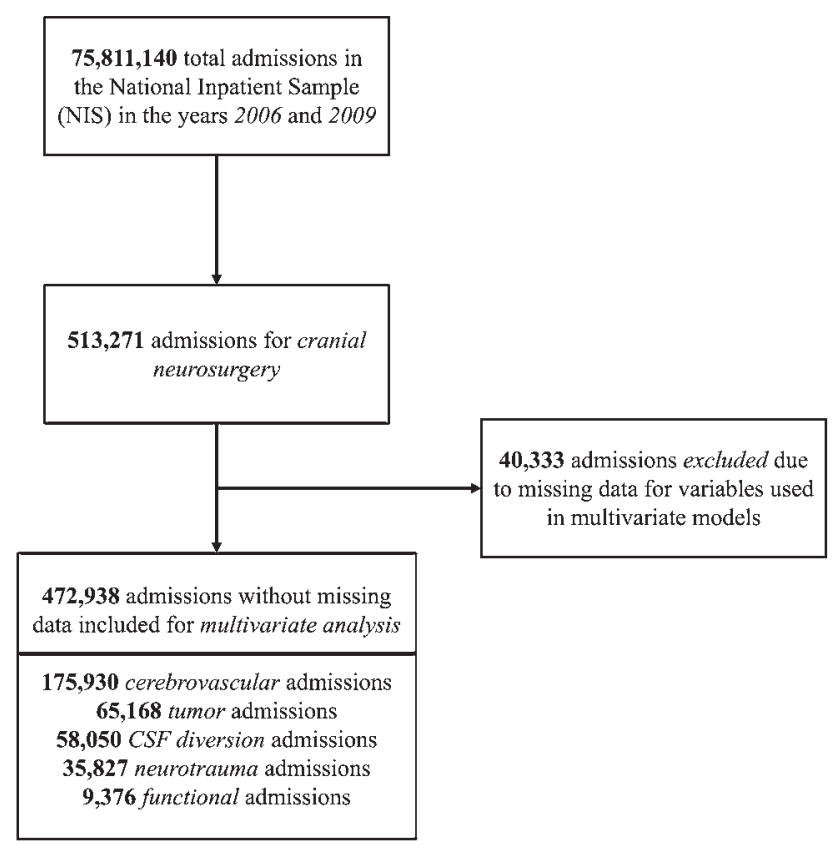

FIG. 1. Study population flow diagram of inclusions and exclusions. Flow diagram shows the selection process of the study population obtained from the NIS of cranial surgery admissions in 2006 and 2009.

sive labor markets. Locally weighted scatterplot smoothing (LOWESS) regression visualized smoothed relationships between HHI and charges or costs.

\section{Statistical Analysis}

We utilized Stata 15 (StataCorp). Using Stata's svy suite of commands, survey weights were applied to admissions to generate national estimates. We first assessed the association between HHI and severity metrics, including All Patient Refined DRG (APR-DRG) severity of illness and risk of mortality scores. Additional disease process-specific severity metrics derived from earlier neurosurgical studies were analyzed for CSF diversion, neurotrauma, aneurysmal subarachnoid hemorrhage, and 4 brain tumor subgroups (Supplementary Table 2). ${ }^{15,23,24}$ Subsequently, we regressed the association between HHI and neurosurgical charges or costs using a gamma distribution with a logistic link function, a model idealized for right-skewed continuous data like inpatient expenditures. All results were reported as $\beta$-coefficients denoting percentage change in the outcome (e.g., $\beta$-coefficient $=1.06$ indicates $+6 \%$ ). Multivariate regression adjusted for 17 confounding variables: age; sex; race; insurance status; ZIP code income level; APR-DRG illness severity and mortality risk; number of comorbidities; hospital bed size, ownership, location, and teaching status; high-volume status; census region; number of procedures; length of stay (LOS); area wage index; and DRG weights. Using secondary diagnoses, the APR-DRG severity of illness and risk of mortality scores rate each admitted patient's extent of physiological decompensation and likelihood of dying, respectively, on a 4-category scale ranging from 1 (minor) to 4 (severe). We quantified comorbidities through a set of 29 comorbidity variables reported in the NIS, using a validated al- gorithm excluding in-hospital complications. ${ }^{25}$ LOS was adjusted due to its relation to care intensity and resources consumed during admission. We used these four variables to adjust for disease severity because of their use for severity adjustment in earlier studies on neurosurgical resource utilization and their well-documented relationship to this outcome. ${ }^{1,26}$ Hospitals were stratified by overall cranial neurosurgery volume following the methods of Yoon et al., with the top $20 \%$ classified as high volume and bottom $80 \%$ classified as low volume. ${ }^{1}$ For a sensitivity analysis of inpatient complications and discharge disposition status as additional confounders, we identified inpatient complications using ICD-9 codes derived from earlier neurosurgical NIS studies and followed the methods of Clement et al. to dichotomize the NIS discharge disposition into favorable versus unfavorable status (Supplementary Table 3). ${ }^{9,14,17}$ All reported results correspond to a -0.1 change in HHI (i.e., an increase in interhospital competition). Statistical significance was maintained at $\mathrm{p}<0.05$.

\section{Results}

\section{Characteristics of Nationwide Cranial Neurosurgery Admissions}

We analyzed 472,938 total admissions for cranial neurosurgery in 2006 and 2009 (Table 1). The most common neurosurgical subspecialty was cerebrovascular (n $=175,930$ or $37.2 \%$ ); the least common was functional $(\mathrm{n}=9376$ or $2.0 \%)$. Patients were an average of $56.2 \pm$ 21.9 years old; the population trended male $(52.5 \%)$ and white (76.1\%). The most common form of insurance was Medicare (43.1\%), followed by private insurance (39.4\%). Most patients were admitted to hospitals classified as large bed size (72.7\%), private nonprofit (75.6\%), urban teaching (69.9\%), and high-volume (70.2\%) institutions and were treated in the South (35.7\%).

Of the 1840 hospitals sampled by the NIS in 2006 and 2009 , our study population was treated at 896 unique hospitals $(48.7 \%)$ nationwide. Each subspecialty, except for functional (181 hospitals), had at least 1 admission in the majority of the 896 hospitals (Supplementary Table 4). The level of interhospital competitive intensity ranged from $\mathrm{HHI}=0.099$ (more competitive) to $\mathrm{HHI}=0.724$ (more monopolistic), with a mean of HHI $=0.298 \pm 0.105$ (Fig. 2). For all hospitals in the NIS, there was no association between HHI and the percentage of total admissions related to cranial neurosurgery $(\mathrm{p}=0.907)$. Hospitals in more competitive markets had greater charge/cost markups $(\beta$ coefficient $=1.10, \mathrm{p}<0.001)$ and were located in areas with higher area wage indices $(\beta$-coefficient $=1.04, p<0.001$; Fig. 3), indicating that more competitive markets are located in "competitive geographies," i.e., geographic regions with higher labor costs. Moreover, admissions in more competitive geographies exhibited higher DRG weights $(\beta$-coefficient $=1.05, \mathrm{p}<0.001)$, denoting increased performance of procedures with higher resource intensity.

Decreasing HHI was associated with greater severity of illness for all admissions as well as cerebrovascular and CSF diversion patients (all $\mathrm{p}<0.05$; Table 2). Cerebrovascular admissions in more competitive markets also had higher scores for risk of mortality (OR 1.19, $\mathrm{p}$ 
TABLE 1. Characteristics of nationwide cranial neurosurgery admissions

\begin{tabular}{|c|c|}
\hline Variable & Value \\
\hline Total no. of admissions & $472,938(100 \%)$ \\
\hline Admitted in 2006 & $242,968(51.4 \%)$ \\
\hline Admitted in 2009 & $229,970(48.6 \%)$ \\
\hline \multicolumn{2}{|l|}{ Neurosurgical subspecialty } \\
\hline Cerebrovascular & $175,930(37.2 \%)$ \\
\hline Tumor & $65,168(13.8 \%)$ \\
\hline CSF diversion & $58,050(12.3 \%)$ \\
\hline Neurotrauma & $35,827(7.6 \%)$ \\
\hline Functional & $9376(2.0 \%)$ \\
\hline Unclassified & $128,587(27.2 \%)$ \\
\hline Age in yrs, mean $\pm S D(I Q R)$ & $56.2 \pm 21.9(44-73)$ \\
\hline \multicolumn{2}{|l|}{ Sex } \\
\hline Male & $248,336(52.5 \%)$ \\
\hline Female & $224,602(47.5 \%)$ \\
\hline \multicolumn{2}{|l|}{ Race } \\
\hline White & $359,858(76.1 \%)$ \\
\hline Hispanic & $45,315(9.6 \%)$ \\
\hline Black & $37,742(8.0 \%)$ \\
\hline Asian & $12,611(2.7 \%)$ \\
\hline Native American & $2194(0.5 \%)$ \\
\hline Other & $15,218(3.2 \%)$ \\
\hline \multicolumn{2}{|l|}{ Insurance } \\
\hline Medicare & $203,730(43.1 \%)$ \\
\hline Private insurance & $186,367(39.4 \%)$ \\
\hline Medicaid & $46,981(9.9 \%)$ \\
\hline Self-pay & $18,022(3.8 \%)$ \\
\hline No charge & $1634(0.3 \%)$ \\
\hline Other & $16,204(3.4 \%)$ \\
\hline \multicolumn{2}{|l|}{ Income level of ZIP code, quartile } \\
\hline 1 (bottom) & $109,102(23.1 \%)$ \\
\hline 2 & $123,218(26.1 \%)$ \\
\hline 3 & $122,601(25.9 \%)$ \\
\hline 4 (top) & $118,017(25.0 \%)$ \\
\hline \multicolumn{2}{|l|}{ APR-DRG illness severity rating } \\
\hline 1 (minor) & $211,641(44.7 \%)$ \\
\hline 2 (moderate) & $146,803(31.0 \%)$ \\
\hline 3 (major) & $72,652(15.4 \%)$ \\
\hline 4 (extreme) & $41,842(8.8 \%)$ \\
\hline \multicolumn{2}{|l|}{ APR-DRG mortality risk rating } \\
\hline 1 (minor) & $291,378(61.6 \%)$ \\
\hline 2 (moderate) & $94,543(20.0 \%)$ \\
\hline 3 (major) & $49,160(10.4 \%)$ \\
\hline 4 (extreme) & $37,857(8.0 \%)$ \\
\hline No. of procedures, mean $\pm \mathrm{SD}(\mathrm{IQR})$ & $3.1 \pm 2.3(1-4)$ \\
\hline \multicolumn{2}{|l|}{ Hospital bed size } \\
\hline Small & $40,427(8.5 \%)$ \\
\hline Medium & $88,861(18.8 \%)$ \\
\hline Large & $343,650(72.7 \%)$ \\
\hline
\end{tabular}

CONTINUED IN NEXT COLUMN »
» CONTINUED FROM PREVIOUS COLUMN

TABLE 1. Characteristics of nationwide cranial neurosurgery admissions

\begin{tabular}{lr}
\hline \multicolumn{1}{c}{ Variable } & \multicolumn{1}{c}{ Value } \\
\hline Hospital ownership & \\
\hline Government, nonfederal & $67,150(14.2 \%)$ \\
\hline Private, nonprofit & $357,402(75.6 \%)$ \\
\hline Private, for profit & $48,386(10.2 \%)$ \\
\hline Hospital location and teaching status & $15,428(3.3 \%)$ \\
\hline Rural & $126,879(26.8 \%)$ \\
\hline Urban, nonteaching & $330,631(69.9 \%)$ \\
\hline Urban, teaching & \\
\hline Hospital case volume & $140,952(29.8 \%)$ \\
\hline Low & $331,986(70.2 \%)$ \\
\hline High & \\
\hline Hospital region & $77,085(16.3 \%)$ \\
\hline Northeast & $112,423(23.8 \%)$ \\
\hline Midwest & $168,782(35.7 \%)$ \\
\hline South & $114,648(24.2 \%)$ \\
\hline West
\end{tabular}

Values are presented as number of admissions (\%) unless otherwise indicated. Percentages may not add up to $100 \%$ due to rounding or missing data. Approximately one-third of admissions did not have sufficient coding data for subspecialty classification and were only included in the overall analysis.

$<0.001)$. More competitive geographies exhibited higher ventriculostomy rates for CSF diversion patients (OR 1.14, $\mathrm{p}=0.004)$. Patients admitted for metastasis in more competitive markets were more likely to have additional extracranial metastases (OR 1.02, $\mathrm{p}=0.044)$, but less likely to have lung cancer $(\mathrm{HHI}=0.98, \mathrm{p}=0.023)$. $\mathrm{HHI}$ was not associated with any other disease process-specific severity metrics.

\section{Trends in Hospital Charges and Costs}

For all cranial neurosurgery admissions, the median inpatient charge was \$44,067 (IQR \$24,442-\$82,761; Fig. 4A) and the median inpatient cost was $\$ 26,101$ (IQR \$14,612-\$46,041; Fig. 4B). LOWESS curves demonstrated that charges $(\$ 76,330$ to $\$ 34,178)$ and costs $(\$ 21,307$ to $\$ 13,845$ ) decreased from $\mathrm{HHI}=0.099$ to $\mathrm{HHI}=0.724$ (Supplementary Fig. 1). Between 2006 and 2009, average neurosurgical charges rose $25 \%$ (\$62,098 to $\$ 77,812$, p $<0.001$; Fig. 4C) and average costs rose 7\% (\$21,385 to $\$ 22,389, \mathrm{p}<0.001$; Fig. 4D). However, in a subgroup of 90 hospitals (10.0\%) with data from both 2006 and 2009, changes in a hospital's HHI over this time period did not correlate with changes in the hospital's average charges $(p=0.265)$ or costs $(p=0.735$; Fig. 4E and F). Average charges significantly rose for all 5 subspecialties between 2006 and 2009 (all p < 0.05), but average costs rose only for cerebrovascular and CSF diversion subpopulations (both $\mathrm{p}<0.05$; Table 3).

\section{Interhospital Competition and Neurosurgical Spending}

After controlling for the effects of patient demograph- 

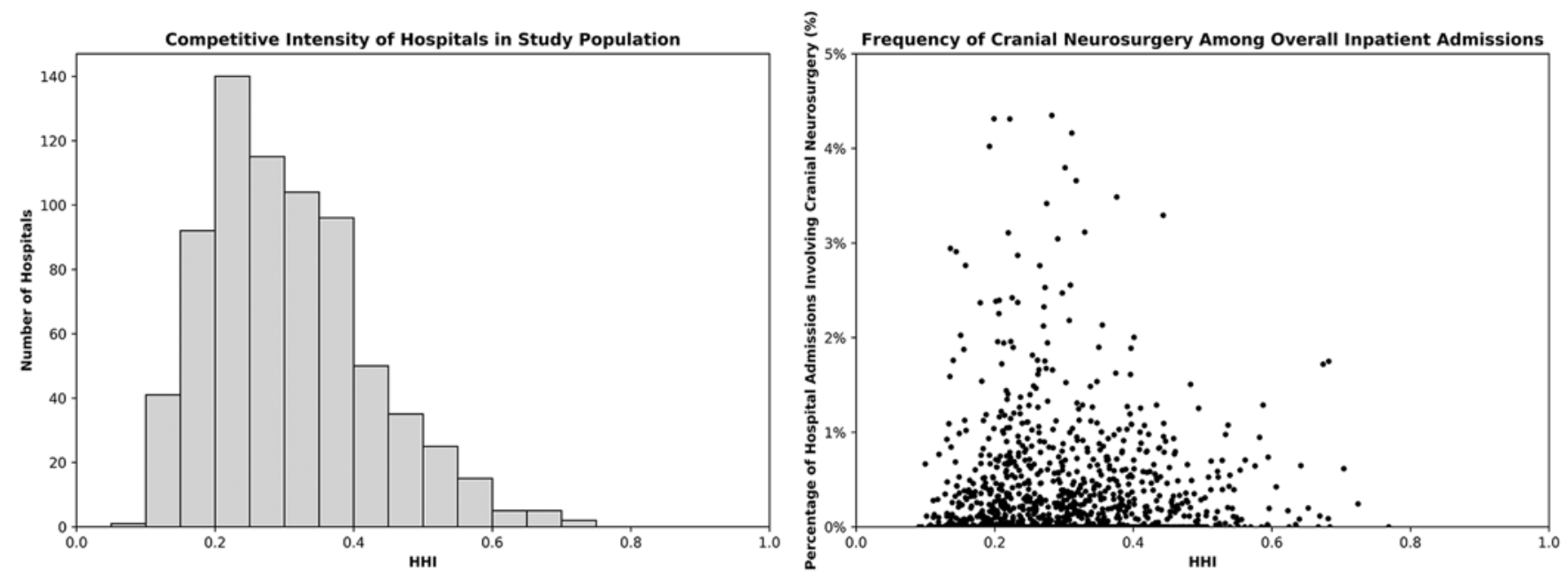

FIG. 2. Left: Histogram of HHI for hospitals in the study population. Distribution of HHI for all 896 national NIS hospitals that performed cranial neurosurgery procedures in 2006 and 2009. Higher HHIs denote more monopolistic hospital markets. Right: Scatterplot of $\mathrm{HHI}$ and percentage of total inpatient admissions involving cranial neurosurgery for all 1840 hospitals sampled in the NIS in 2006 and 2009, including hospitals that did not perform neurosurgery.

ics, hospital characteristics, case severity, and economic factors, greater interhospital competition was associated with a $7 \%$ increase in inpatient charges $(\beta$-coefficient $=$ $1.07, \mathrm{p}<0.001$ ), roughly $\$ 4924$ more per patient (Fig. 5). More competitive markets exhibited increased charges for all 5 subspecialties: cerebrovascular $(\beta$-coefficient $=1.08$, $\mathrm{p}<0.001)$, tumor $(\beta$-coefficient $=1.05, \mathrm{p}=0.039)$, CSF diversion $(\beta$-coefficient $=1.08, \mathrm{p}<0.001)$, neurotrauma $(\beta$-coefficient $=1.07, \mathrm{p}<0.001)$, and functional neurosurgery $(\beta$-coefficient $=1.11, \mathrm{p}=0.037)$. The corresponding cost increases were approximately $\$ 4373, \$ 3880, \$ 7246$, $\$ 7001$, and $\$ 7200$ per case for cerebrovascular, tumor, CSF diversion, neurotrauma, and functional admissions, respectively. Despite its relationship with inpatient charges, HHI was not significantly associated with inpatient costs for the overall study population or any subspecialty, with the exception of more competitive markets having increased costs for CSF diversion surgery $(\beta$-coefficient $=$ 1.03 , p = 0.021; Fig. 5).

HHI was not significantly associated with improvements in inpatient mortality, discharge disposition, or inpatient complications for the overall study population or any subspecialty, except for decreased mortality for tumor patients in more competitive markets $(\mathrm{OR} 0.78, \mathrm{p}=$ 0.026; Supplementary Fig. 2). Moreover, higher interhospital competition was associated with elevated LOS for all cranial neurosurgery admissions $(\beta$-coefficient $=1.06, \mathrm{p}$ $<0.001$ ) and every subspecialty except functional (all $\mathrm{p}<$ $0.05)$. While LOS was already included in our multivariate models, we performed a sensitivity analysis to account
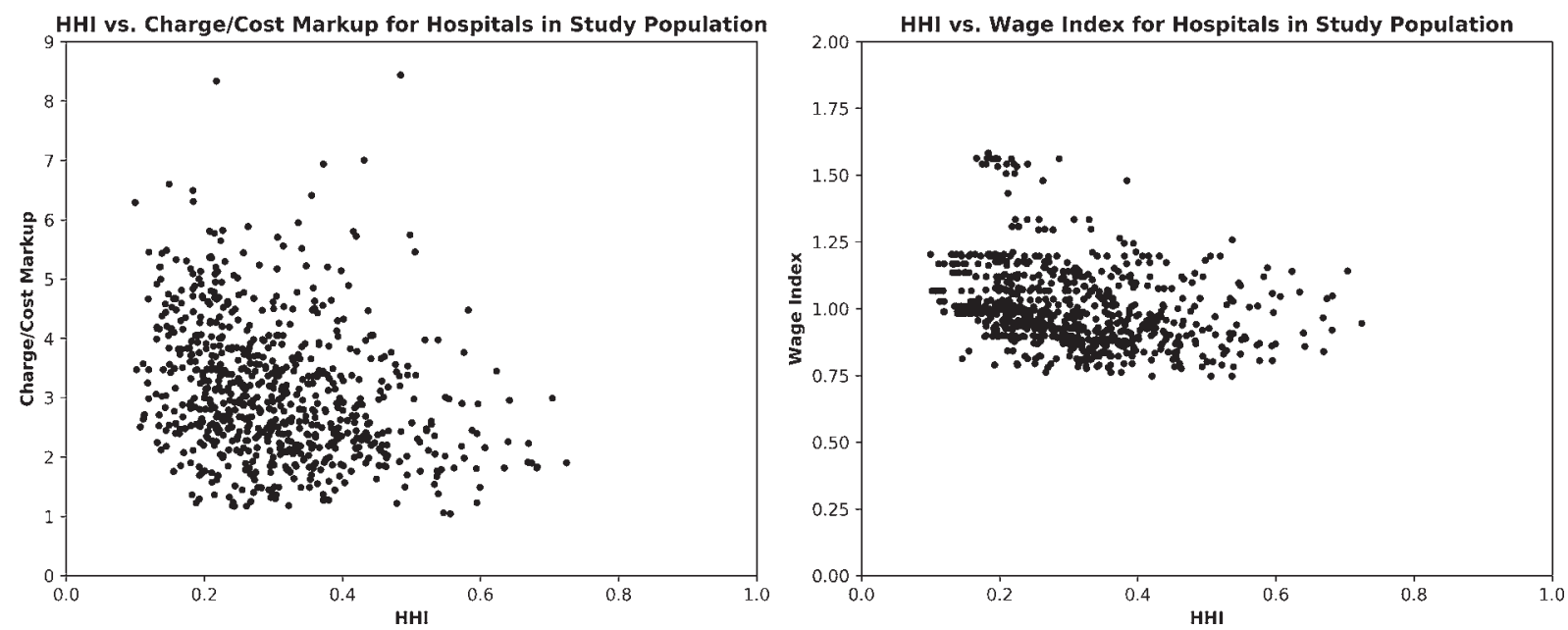

FIG. 3. Relationship between $\mathrm{HHI}$ and charge/cost markup or wage index. Left: Scatterplot of $\mathrm{HHI}$ and charge/cost markup for each hospital. A higher charge/cost markup indicates that for a set cost, a hospital billed the patient for a greater amount. Right: Scatterplot of $\mathrm{HHI}$ and wage index for each hospital. The wage index reflects geographic variation in hospital wage levels for a hospital's location compared to the national average, with a greater wage index signifying more expensive labor markets. 
TABLE 2. Association of HHI with neurosurgical case severity

\begin{tabular}{|c|c|c|c|}
\hline Variable & $\begin{array}{c}\text { No. of } \\
\text { Admissions }\end{array}$ & $\begin{array}{c}\text { Severity Score, OR or Linear } \\
\text { Change }[95 \% \mathrm{Cl}]\end{array}$ & p Value \\
\hline All admissions & 472,938 & & \\
\hline APR-DRG severity of illness & & $1.12[1.07-1.17]$ & $<0.001$ \\
\hline APR-DRG risk of mortality & & 1.04 [0.99-1.08] & 0.083 \\
\hline Cerebrovascular & 175,930 & & \\
\hline APR-DRG severity of illness & & $1.27[1.17-1.37]$ & $<0.001$ \\
\hline APR-DRG risk of mortality & & $1.19[1.11-1.27]$ & $<0.001$ \\
\hline Tumor & 65,168 & & \\
\hline APR-DRG severity of illness & & $0.97[0.91-1.03]$ & 0.288 \\
\hline APR-DRG risk of mortality & & $0.96[0.90-1.03]$ & 0.247 \\
\hline CSF diversion & 58,050 & & \\
\hline APR-DRG severity of illness & & $1.09[1.03-1.16]$ & 0.004 \\
\hline APR-DRG risk of mortality & & $1.08[0.99-0.17]$ & 0.054 \\
\hline Ventriculostomy performed & & 1.14 [1.04-1.25] & 0.004 \\
\hline Neurotrauma & 35,827 & & \\
\hline APR-DRG severity of illness & & $1.02[0.96-1.08]$ & 0.601 \\
\hline APR-DRG risk of mortality & & $0.97[0.92-1.03]$ & 0.394 \\
\hline ISS & & $-0.08^{*}[-0.25$ to 0.09$]$ & 0.383 \\
\hline Functional & 9376 & & \\
\hline APR-DRG severity of illness & & $1.15[0.86-1.54]$ & 0.352 \\
\hline APR-DRG risk of mortality & & $0.98[0.78-1.22]$ & 0.834 \\
\hline Aneurysmal SAH & 23,530 & & \\
\hline NIS SAH outcome measure & & $-0.13^{*}[-0.33$ to 0.08$]$ & 0.226 \\
\hline Primary brain tumor & 35,493 & & \\
\hline Hemiplegia or hemiparesis at presentation & & $1.00[0.99-1.01]$ & 0.616 \\
\hline Malignant status & & $0.99[0.97-1.01]$ & 0.300 \\
\hline Meningioma & 21,910 & & \\
\hline Hemiplegia or hemiparesis at presentation & & $0.99[0.97-1.01]$ & 0.098 \\
\hline Metastasis & 20,461 & & \\
\hline Hemiplegia or hemiparesis at presentation & & $1.00[0.99-1.01]$ & 0.771 \\
\hline Extracranial metastases at presentation & & $1.02[1.01-1.03]$ & 0.044 \\
\hline Lung cancer diagnosis & & $0.98[0.96-0.99]$ & 0.023 \\
\hline Acoustic neuroma & 5011 & & \\
\hline Hydrocephalus at presentation & & $0.97[0.94-1.01]$ & 0.074 \\
\hline Neurofibromatosis diagnosis & & $1.00[0.99-1.01]$ & 0.616 \\
\hline
\end{tabular}

ISS = Injury Severity Score; SAH = subarachnoid hemorrhage.

The univariate association between $\mathrm{HHI}$ and severity variables was analyzed. For APR-DRG severity of illness and risk of mortality scores (4-level ordinal variables), ordinal logistic regression was used and ORs were reported. For binary outcomes, logistic regression was used and ORs were reported. All results correspond to a -0.1 change in $\mathrm{HHI}$ (i.e., increase in interhospital competition).

* Linear regression and linear change reported for continuous outcomes.

for any residual confounding due to potential interhospital differences in surgical outcomes by adding inpatient complication and discharge disposition status as additional confounding variables. HHI was associated with higher charges for the overall study population and all subspecialties, while HHI was only associated with costs for CSF diversion (Supplementary Fig. 3).

\section{Discussion}

Healthcare expenditures have grown at rates above the gross domestic product growth in the United States for several decades. ${ }^{6}$ Spending for surgical care alone is expected to encompass $7 \%$ of the US economy by $2025 .{ }^{27}$ Similar trends have been observed for neurosurgical procedures. We demonstrate a $25 \%$ increase in average charges and a $7 \%$ increase in average costs for inpatient admissions for cranial neurosurgery in just 3 years. The rise is especially pronounced for charges, with significant increases independently observed across 5 cranial neurosurgery subspecialties. As patient cost-sharing has accelerated the past 2 decades, these trends have led to a sharp rise in patient 

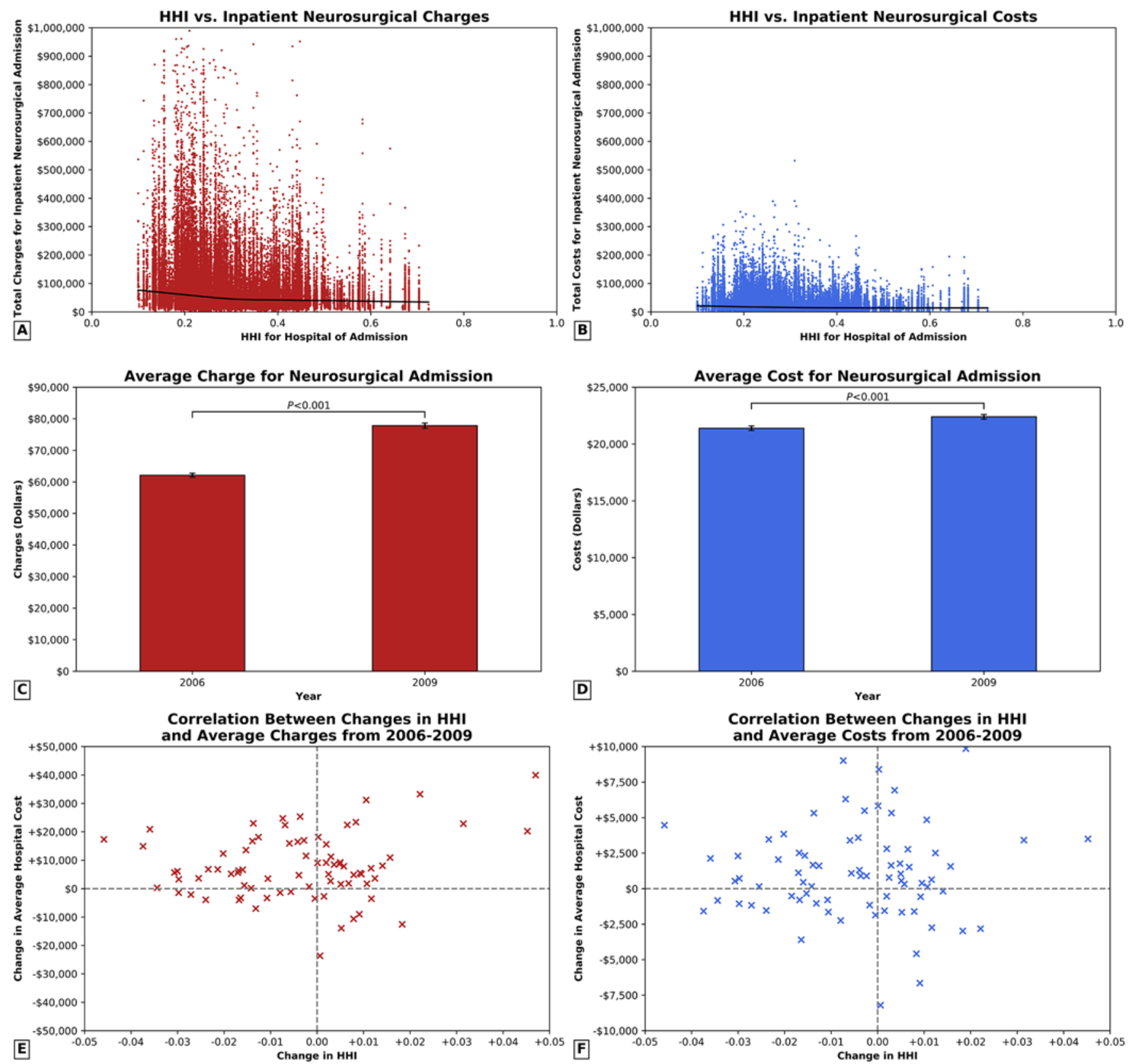

FIG. 4. Neurosurgical charges and costs in 2006 and 2009. A: Scatterplot of $\mathrm{HHI}$ and inpatient neurosurgical charges for each neurosurgical admission, with an overlaid LOWESS curve. B: Scatterplot of HHI and inpatient neurosurgical costs for each neurosurgical admission, with an overlaid LOWESS curve. Scatterplots with vertical axes scaled to $\$ 100,000$ for better visualization of the LOWESS curves are displayed in Supplementary Figure 1. C: Average charges increased significantly over 3 years from $\$ 62,098$ to $\$ 77,812$ ( $p<0.001$ ). D: Average costs increased significantly over 3 years from $\$ 21,385$ to $\$ 22,389(p<0.001)$. $\mathrm{E}$ : Scatterplot of change in $\mathrm{HHI}$ and change in average charges for the 90 hospitals. F: Scatterplot of change in $\mathrm{HHI}$ and change in average costs for the 90 hospitals. Figure is available in color online only.

out-of-pocket spending for neurosurgical procedures. For example, Mooney et al. found that craniotomies are associated with the greatest expected patient payments, ${ }^{2}$ a situation that emphasizes the need to analyze in detail the drivers of cost growth in cranial neurosurgery. A parallel trend has been the consolidation of hospitals and practices, driven in part as one logical response to the 2010 Patient Protection and Affordable Care Act (ACA). ${ }^{4}$ An estimated
90 hospital consolidations have occurred annually in the past decade, and one-fifth of all US hospitals are projected to seek a merger in the next 5 years. ${ }^{28,29}$ Earlier research has suggested that these mergers and the increasing employment of physicians may increase healthcare prices by augmenting the bargaining power of healthcare systems with insurers. ${ }^{30}$

Although competition has been generally understood 
TABLE 3. Changes in average neurosurgical charges and costs from 2006 to 2009

\begin{tabular}{|c|c|c|c|c|c|c|}
\hline \multirow[b]{2}{*}{ Subspecialty } & \multicolumn{3}{|c|}{ Charges } & \multicolumn{3}{|c|}{ Costs } \\
\hline & 2006 & 2009 & $p$ Value & 2006 & 2009 & $p$ Value \\
\hline All admissions & $\$ 62,098 \pm 313$ & $\$ 77,812 \pm 401$ & $<0.001$ & $\$ 21,385 \pm 101$ & $\$ 22,389 \pm 103$ & $<0.001$ \\
\hline Cerebrovascular & $\$ 48,929 \pm 476$ & $\$ 60,223 \pm 638$ & $<0.001$ & $\$ 16,804 \pm 157$ & $\$ 17,510 \pm 168$ & 0.002 \\
\hline Tumor & $\$ 69,705 \pm 777$ & $\$ 84,064 \pm 886$ & $<0.001$ & $\$ 23,939 \pm 240$ & $\$ 24,544 \pm 222$ & 0.064 \\
\hline CSF diversion & $\$ 78,960 \pm 1273$ & $\$ 100,864 \pm 1625$ & $<0.001$ & $\$ 27,404 \pm 413$ & $\$ 29,043 \pm 438$ & 0.007 \\
\hline Neurotrauma & $\$ 90,029 \pm 1337$ & $\$ 109,295 \pm 1770$ & $<0.001$ & $\$ 30,834 \pm 429$ & $\$ 30,489 \pm 436$ & 0.572 \\
\hline Functional & $\$ 62,118 \pm 1529$ & $\$ 68,563 \pm 1534$ & 0.004 & $\$ 21,348 \pm 493$ & $\$ 20,416 \pm 443$ & 0.161 \\
\hline
\end{tabular}

Values are presented as mean \pm SEM unless otherwise indicated. Significant differences in average costs or charges were evaluated using unpaired t-tests.

to drive down prices, the impact of these market-level changes on neurosurgical spending is likely complex and multifactorial. Paradoxically, our results, with financial data from a national cohort of nearly 500,000 patients, before and during the Great Recession of 2007-2009, show that cranial procedures in more competitive markets had higher inpatient charges, without increases in expenses, except for CSF diversion surgery. This trend was observed for overall admissions and across all subspecialties. Chang et al. found similar results for five general surgery procedures. ${ }^{11}$ These results suggest there may be additional factors driving patient billing unrelated to differences in resource utilization. We propose two potential explanations.

The first possible explanation for patient billing increases unrelated to resource utilization is that interhospital competition may drive institutional spending in areas that increase patient billing, selectively elevating inpatient charges. An example of these "hidden costs" is hospital marketing. Several studies have suggested that competitive pressures in more hospital markets encourage institutions to invest in advertising to reach patients directly to maintain and grow their market share.9,11,31 The impact of marketing intensity on higher patient satisfaction scores is pronounced in competitive markets. ${ }^{31}$ Investment in these nonclinical expenditures may contribute to higher charges in these more competitive geographies. Another driver of elevated charges is additional billing generated by passthrough or add-on payments for new medical technologies. For example, in the New Technology Add-On Payment Program, CMS allows separate, additional billing of certain novel technologies to encourage adoption before bundled payment levels have been adjusted to reflect the costs of these new techniques. ${ }^{32}$ While these measures most directly affect public insurance programs, the majority of our study population was made up of patients affected by this change, and private payer reimbursement patterns are influenced by these public programs. ${ }^{30} \mathrm{Neu}-$ rosurgical supplies that qualify for these payments include hemostatic agents and dural grafts. Competitive markets may have a "medical arms race" that encourages hospitals to attract patients by acquiring novel technologies that may have little or no additional efficacy, contributing to higher patient billing. ${ }^{9-11,33,34}$ However, more detailed data on hospital expenditures than are available in NIS are needed to examine these "hidden costs."

A second explanation for billing increases is that elevat- ed charges in more competitive markets may reflect higher charge/cost markups and, consequently, greater profit margins. There is substantial interhospital variation in hospitals' charge masters, the comprehensive listings of items billable to the patient or health insurance provider. ${ }^{35,36}$ While the national average is 3.4-fold, markups above 10 -fold have been reported for several institutions. ${ }^{36}$ The average markup has doubled since 1984, making growth in charge-master rates a compelling explanation for acceleration in inpatient charges. ${ }^{36}$ Chang et al. postulated that hospitals in more competitive markets charge more for services to offset the financial challenges of competition. ${ }^{11}$ Analysis of confounders in our multivariate model demonstrated that hospitals in competitive geographies face further difficulties due to higher wage indices and patient DRG weights, denoting greater labor costs and higher procedural intensity, respectively. Accordingly, we found that a -0.1 change in HHI was associated with a $10 \%$ increase in a hospital's charge/cost markup for cranial neurosurgery nationwide. Elevation of neurosurgical charges in competitive markets may be the result of increased billing to improve margins.

Interestingly, our study results and those of Chang et al. contradict the findings of Robinson, who determined that competition was associated with lower charges and profitability for 6 cardiac and orthopedic surgery procedures. ${ }^{7}$ Robinson examined a small cohort of 61 hospitals in 8 states and argued that higher charges are expected in more monopolistic markets, where hospitals have greater negotiating power. However, in competitive geographies, newer technologies and investments in marketing and patient satisfaction may allow hospitals in crowded markets to exercise significant bargaining power. ${ }^{31,33} \mathrm{Wu}$ found that 5 years after the closure of rival institutions, hospitals in the 1990 s experienced, on average, a permanent price increase of $4 \% .{ }^{37}$ In addition, a multidecade study of heart disease patients found that interhospital competition was associated with lower expenditures after 1990, a period with a particularly high focus on managed care, but not before. ${ }^{38}$ Other studies have suggested that in more recent years, the decline of the managed care environment has prompted hospitals to shift from price competition to nonprice competition strategies, like new technology or heightened amenities.11,33 Our data for cranial neurosurgery and those of Durand et al. for lumbar fusion suggest that one consequence of these changes is that hospital 

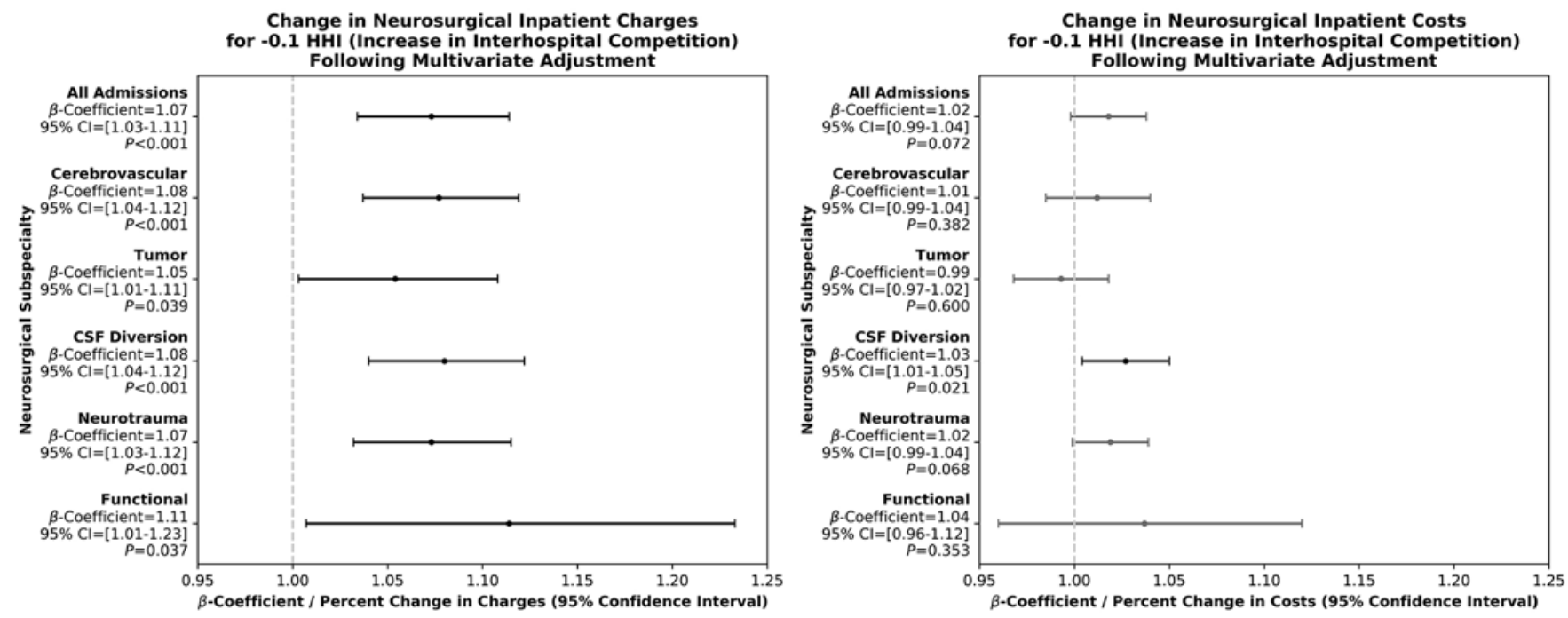

FIG. 5. Association between $\mathrm{HHI}$ and neurosurgical charges and costs. Left: $\beta$-Coefficients and $95 \% \mathrm{Cls}$ indicating the percentage change in charges per -0.1 change in $\mathrm{HHI}$ (increase in interhospital competition). Right: $\beta$-Coefficients and $95 \% \mathrm{Cls}$ indicating the percentage change in costs per -0.1 change in $\mathrm{HHI}$ (increase in interhospital competition). All associations were adjusted for patient demographics, hospital characteristics, case severity, and economic factors.

competitive intensity is associated with elevated charges. ${ }^{9}$ Nonprice competition, rather than competition through enhanced outcomes, ${ }^{5,11,33}$ may explain why we did not find an association between HHI and mortality, disposition, or complications, except for brain tumor craniotomy mortality. Interhospital competition likely influences hospital charges through several mechanisms, with variable effects on prices; further research is warranted to characterize interplay between these factors.

An important consideration regarding the findings of the present study is that for the calculation of HHI, all individual hospitals were considered competitors, even if they belong to the same hospital system. Several studies have indicated that large institutions or hospital systems can increase their negotiating power relative to competitors in the same locality. ${ }^{6,7}$ Consequently, a market with many hospitals and a low HHI (significant competition) may paradoxically function as a monopolistic market if the majority of these hospitals are owned by a single system. These HHI values may not capture competition changes like the acquisition of an institution by another system. These ownership structures, for which the NIS does not have data, may have influenced our findings on neurosurgical charges. However, the HHI metric we used defined markets by patient flow, instead of geographic borders, so even geographically adjacent hospitals had distinct market borders. The use of this metric may mitigate the confounding influence of integrated systems, which are more likely to operate in geographic proximity, although this is not always the case. We aim to elucidate the role of hospital system ownership in future work.

Another concern is that HHI values were calculated based on overall patient discharges, as there are insufficient NIS data to calculate neurosurgery-specific HHI values reflecting competitive dynamics for these procedures specifically. Because cranial neurosurgery admissions were treated in only $48.7 \%$ of sampled hospitals nation- wide, there are likely fewer competitors, and the catchment areas for neurosurgical procedures are presumably larger than those of more common procedures. This may have been especially true for functional neurosurgery, which was performed at only $20.2 \%$ of hospitals in our study. Because neurosurgical admissions may be overrepresented at certain institution types like larger urban hospitals, the relationship between HHI values for overall admissions and values for neurosurgery may not necessarily be linear or monotonic. Nevertheless, we determined that a hospital's percentage of admissions associated with cranial neurosurgery did not differ depending on its level of competition. Moreover, competitive forces based on overall discharges may still impact neurosurgical practice, as these dynamics impact global processes of care and decision-making, such as the adoption of newer technologies. ${ }^{10}$ This may explain how these nonspecific HHI values have also been shown to predict higher charges across other procedures with higher admission volume, including lumbar fusion and general surgery procedures. ${ }^{9,11}$ It remains possible that the association between higher interhospital competition and elevated costs may be primarily driven by factors intrinsic to more competitive hospital markets, as opposed to differences in interhospital competition itself. Future research utilizing neurosurgery-specific HHI values to characterize market practice patterns is warranted.

Despite interhospital competition not being significantly associated with inpatient costs for overall cranial neurosurgery admissions or most subspecialties, CSF diversion surgery costs were elevated in more competitive markets. While Henke et al. demonstrated that markets with higher competition had lower costs for inpatient admissions as a whole, ${ }^{8}$ other studies have shown elevated costs following certain procedures like breast reconstruction and laryngectomy in these markets. ${ }^{39,40}$ Although interhospital competition may curtail costs by improving efficiency of resource use, ${ }^{38}$ this reduction of costs may be attenuated 
in more competitive markets by the medical arms race, ${ }^{33}$ enhanced ICU utilization, spending on patient amenities, ${ }^{41}$ or service duplication between hospitals in the same market ${ }^{42}$ Technology adoption through the medical arms race may reduce LOS and costs in competitive markets by shifting patients toward less-invasive procedures. However, the elevated LOS we observed in more competitive geographies suggests that other factors in these markets, like higher levels of care, may attenuate or reverse these beneficial effects. Pronounced intermarket differences in practice patterns and adoption of technologies such as antibiotic-impregnated catheters and programmable shunts, granular data not included in NIS, may explain why higher costs in more competitive markets were observed only for CSF diversion patients in our study. Ventriculostomy rates were also elevated in more competitive markets, and CSF diversion had the highest increases in average charges and costs from 2006 to 2009 among all subspecialties, potentially reflecting a high innovation rate. Alternatively, due to CSF diversion patients exhibiting higher severity of illness scores in more competitive markets, elevated costs in these geographies may also reflect residual confounding of greater case complexity. Although we did not find any differences in costs for cerebrovascular admissions related to competition, an NIS analysis of unruptured aneurysm surgery, in a smaller and more homogenous cohort, found that more competitive markets had higher costs. ${ }^{43}$ Future characterization of the competition-cost link for specific neurosurgical procedures is warranted.

This study and earlier research highlight several patient and policy implications. We found that in spite of no differences in resource utilization, more competitive markets bill neurosurgical patients at higher rates than do hospitals in less competitive markets. Due to challenges in patient access posed by increasing out-of-pocket expenses, ${ }^{2,3}$ it is important to pinpoint and reduce drivers of billing heterogeneity between different hospitals and markets. Our work also has implications for quality, safety, and outcome analyses, because competition-driven increases in nonclinical spending may come at the expense of clinical service and quality improvement investment. ${ }^{44}$ Moreover, to counteract the pervasiveness of nonprice competition, methods to increase interhospital competition on the grounds of quality may include regionalization of neurosurgical care at high-performing institutions, insurance models that incentivize quality improvement by directly contracting with employers, and improved reporting of meaningful and durable surgical outcomes. However, the difficulty that patients, referring physicians, and payers have in obtaining consistent comparative data on expense and quality suggests that efforts at comparison like our study can facilitate decision-making regarding both individual and public policies.

\section{Study Limitations}

Because the NIS does not have a service line variable, DRG codes were used to select cranial procedures. However, the DRGs used for study inclusion have been validated by earlier NIS studies of neurosurgery; the procedures selected represent those commonly seen in neurosurgical practice. ${ }^{11,13}$ NIS has limited disease- and specialty-specif- ic severity data. While we used variables like APR-DRG severity of illness and risk of mortality scores to control for interhospital differences in case complexity, the elevation of these scores in more competitive markets may be evidence of residual confounding for which the NIS did not have enough granular, neurosurgery-specific data. Nevertheless, higher patient severity would likely impact both inpatient costs and charges, so these differences do not explain why charges were selectively elevated in competitive markets. The relationship between interhospital competition and neurosurgical expenditures may be impacted by the influence of competition on inpatient outcomes. However, our sensitivity analysis assessing inpatient complications and discharge disposition found no changes in significance. Additionally, the cost-to-charge ratio for each hospital was calculated from financial data for all inpatient admissions, instead of just neurosurgical patients. However, a report from the CMS that calculated cost-to-charge ratios for each individual DRG shows there is minimal variation between the general cost-to-charge ratios used in this study and DRG-specific cost-to-charge ratios, including those for neurosurgery. ${ }^{45}$ Finally, HHI values were reported by NIS only through 2009. Due to changes over the past decade, with accelerating healthcare industry consolidation since the ACA's enactment, this study may not entirely reflect competitive pressures and impacts on current neurosurgical practice. ${ }^{30,40}$ Future research may benefit from specialty-specific and more recent HHI measurements. ${ }^{4,28,29}$ Nevertheless, our study demonstrates, in a nationally generalizable cohort of 472,938 cranial neurosurgery hospital admissions, that elevated interhospital competition is predictive of higher inpatient charges for cranial neurosurgery overall, but not increased costs.

\section{Conclusions}

Inpatient charges and costs have risen significantly for neurosurgical admissions. Evidence from nearly 500,000 patients indicates that more competitive markets exhibited higher charges for cranial neurosurgery admissions as a whole and within 5 subspecialties. However, interhospital competition was not associated with differences in underlying costs except for CSF diversion surgery. Future studies should examine how competition between hospitals influences different areas of inpatient spending in order to improve the value of neurosurgical care.

\section{Acknowledgments}

We would like to thank the HCUP for their role in clarifying methodological questions related to the HHI and its calculation during this present study's analyses.

\section{References}

1. Yoon JS, Tang OY, Lawton MT. Volume-cost relationship in neurosurgery: analysis of 12,129,029 admissions from the National Inpatient Sample. World Neurosurg. 2019;129:e791e802.

2. Mooney MA, Yoon S, Cole T, et al. Cost transparency in neurosurgery: a single-institution analysis of patient out-ofpocket spending in 13673 consecutive neurosurgery cases. Neurosurgery. 2019;84(6):1280-1289. 
3. Collins SR, Bhupal HK, Doty MM. Health Insurance Coverage Eight Years After the ACA. The Commonwealth Fund; 2019. Accessed July 8, 2020. https://www.commonwealthfund.org/publications/issue-briefs/2019/feb/health-insurancecoverage-eight-years-after-aca

4. Kim DH, Dagi TF, Bean JR. Neurosurgical practice in transition: a review. Neurosurgery. 2017;80(4S):S4-S9.

5. Beaulieu ND, Dafny LS, Landon BE, et al. Changes in quality of care after hospital mergers and acquisitions. $N$ Engl $J$ Med. 2020;382(1):51-59.

6. Ly DP, Cutler DM. Factors of U.S. hospitals associated with improved profit margins: an observational study. J Gen Intern Med. 2018;33(7):1020-1027.

7. Robinson JC. Hospital market concentration, pricing, and profitability in orthopedic surgery and interventional cardiology. Am J Manag Care. 2011;17(6 Spec No.):e241-e248.

8. Henke RM, Maeda JL, Marder WD, et al. Medicare and commercial inpatient resource use: impact of hospital competition. Am J Manag Care. 2013;19(6):e238-e248.

9. Durand WM, Johnson JR, Li NY, et al. Hospital competitive intensity and perioperative outcomes following lumbar spinal fusion. Spine J. 2018;18(4):626-631.

10. Wright JD, Tergas AI, Hou JY, et al. Effect of regional hospital competition and hospital financial status on the use of robotic-assisted surgery. JAMA Surg. 2016;151(7):612-620.

11. Chang DC, Shiozawa A, Nguyen LL, et al. Cost of inpatient care and its association with hospital competition. J Am Coll Surg. 2011;212(1):12-19.

12. Overview of the National (Nationwide) Inpatient Sample (NIS). Healthcare Cost and Utilization Project. Accessed July 8, 2020. https://www.hcup-us.ahrq.gov/nisoverview.jsp

13. Cowan JA Jr, Chandler WF. Changing trends in the use and costs of procedures performed by neurosurgeons in the United States. Clin Neurosurg. 2007;54:209-211.

14. Davies JM, Lawton MT. Improved outcomes for patients with cerebrovascular malformations at high-volume centers: the impact of surgeon and hospital volume in the United States, 2000-2009. J Neurosurg. 2017;127(1):69-80.

15. Curry WT Jr, Carter BS, Barker FG II. Racial, ethnic, and socioeconomic disparities in patient outcomes after craniotomy for tumor in adult patients in the United States, 1988-2004. Neurosurgery. 2010;66(3):427-438.

16. Smith ER, Butler WE, Barker FG II. In-hospital mortality rates after ventriculoperitoneal shunt procedures in the United States, 1998 to 2000: relation to hospital and surgeon volume of care. J Neurosurg. 2004;100(2)(Suppl Pediatrics): 90-97.

17. Clement RC, Carr BG, Kallan MJ, et al. Volume-outcome relationship in neurotrauma care. J Neurosurg. 2013;118(3): 687-693.

18. Englot DJ, Ouyang D, Garcia PA, et al. Epilepsy surgery trends in the United States, 1990-2008. Neurology. 2012; 78(16):1200-1206.

19. Sharma M, Ambekar S, Guthikonda B, et al. Regional trends and the impact of various patient and hospital factors on outcomes and costs of hospitalization between academic and nonacademic centers after deep brain stimulation surgery for Parkinson's disease: a United States Nationwide Inpatient Sample analysis from 2006 to 2010. Neurosurg Focus. 2013; 35(5):E2.

20. Houchens R. Missing Data Methods for the NIS and the SID. US Agency for Healthcare Research and Quality; 2015.

21. Herfindahl-Hirschman Index. US Department of Justice. Accessed July 8, 2020. https://www.justice.gov/atr/herfindahlhirschman-index

22. Cost-to-charge ratio files. Healthcare Cost and Utilization Project. Accessed July 8, 2020. https://www.hcup-us.ahrq. gov/db/state/costtocharge.jsp

23. Greene NH, Kernic MA, Vavilala MS, Rivara FP. Valida- tion of ICDPIC software injury severity scores using a large regional trauma registry. Inj Prev. 2015;21(5):325-330.

24. Washington CW, Derdeyn CP, Dacey RG Jr, et al. Analysis of subarachnoid hemorrhage using the Nationwide Inpatient Sample: the NIS-SAH Severity Score and Outcome Measure. J Neurosurg. 2014;121(2):482-489.

25. Elixhauser A, Steiner C, Harris DR, Coffey RM. Comorbidity measures for use with administrative data. Med Care. 1998;36(1):8-27.

26. Zygourakis CC, Liu CY, Yoon S, et al. Analysis of cost variation in craniotomy for tumor using 2 national databases. Neurosurgery. 2017;81(6):972-979.

27. Muñoz E, Muñoz W III, Wise L. National and surgical health care expenditures, 2005-2025. Ann Surg. 2010;251(2): 195-200.

28. Xu T, Wu AW, Makary MA. The potential hazards of hospital consolidation: implications for quality, access, and price. JAMA. 2015;314(13):1337-1338.

29. Chang V, Blackwell RH, Yau RM, et al. Variable surgical outcomes after hospital consolidation: implications for local health care delivery. Surgery. 2016;160(5):1155-1161.

30. Baker LC, Bundorf MK, Kessler DP. Vertical integration: hospital ownership of physician practices is associated with higher prices and spending. Health Aff (Millwood). 2014; 33(5):756-763.

31. Huppertz JW, Bowman RA, Bizer GY, et al. Hospital advertising, competition, and HCAHPS: does it pay to advertise? Health Serv Res. 2017;52(4):1590-1611.

32. Clyde AT, Bockstedt L, Farkas JA, Jackson C. Experience with Medicare's new technology add-on payment program. Health Aff (Millwood). 2008;27(6):1632-1641.

33. Devers KJ, Brewster LR, Casalino LP. Changes in hospital competitive strategy: a new medical arms race? Health Serv Res. 2003;38(1 Pt 2):447-469.

34. Li H, Gail MH, Braithwaite RS, et al. Are hospitals "keeping up with the Joneses"?: assessing the spatial and temporal diffusion of the surgical robot. Healthc (Amst). 2014;2(2): 152-157.

35. Medicare Payment Advisory Committee. Hospital Inpatient and Outpatient Services: Assessing Payment Adequacy and Updating Payments. Medicare Payment Advisory Committee; 2018.

36. Bai G, Anderson GF. Extreme markup: the fifty US hospitals with the highest charge-to-cost ratios. Health Aff (Millwood). 2015;34(6):922-928.

37. Wu VY. The price effect of hospital closures. Inquiry. 2008; 45(3):280-292.

38. Kessler DP, McClellan MB. Is hospital competition socially wasteful? Q J Econ. 1999;115:577-615.

39. Cerullo M, Sheckter CC, Canner JK, et al. Is bigger better?: the effect of hospital consolidation on index hospitalization costs and outcomes among privately insured recipients of immediate breast reconstruction. Ann Surg. 2019;270(4): 681-691.

40. Gourin CG, Vosler PS, Mandal R, et al. Association between hospital market concentration and costs of laryngectomy. JAMA Otolaryngol Head Neck Surg. 2019;145(10):939-947.

41. Goldman DP, Vaiana M, Romley JA. The emerging importance of patient amenities in hospital care. $N$ Engl J Med. 2010;363(23):2185-2187.

42. Connor RA, Feldman RD, Dowd BE. The effects of market concentration and horizontal mergers on hospital costs and prices. Int J Econ Bus. 1998;5(2):159-180.

43. Tang $\mathrm{O}$, Yoon $\mathrm{S}$, Durand $\mathrm{W}$, et al. Interhospital competition predicts treatment and outcomes for unruptured aneurysms. Paper presented at: 2019 AANS Annual Scientific Meeting; April 13-17, 2019; San Diego, CA.

44. Mukamel DB, Zwanziger J, Bamezai A. Hospital competition, resource allocation and quality of care. BMC Health Serv Res. 2002;2(1):10. 
45. Sun Y, Friedman B. Tools for More Accurate Inpatient Cost Estimates With Databases, 2009. US Agency for Healthcare Research and Quality; 2019.

\section{Disclosures}

The authors report no conflict of interest concerning the materials or methods used in this study or the findings specified in this paper.

\section{Author Contributions}

Conception and design: Toms, Tang, Rivera Perla. Acquisition of data: Tang, Lim, Yoon, Weil. Analysis and interpretation of data: Toms, Tang, Lim, Yoon, Weil. Drafting the article: Toms, Tang, Rivera Perla, Weil. Critically revising the article: all authors. Reviewed submitted version of manuscript: all authors. Approved the final version of the manuscript on behalf of all authors: Toms. Statistical analysis: Tang, Lim, Yoon, Weil. Study supervision: Toms.

\section{Supplemental Information \\ Online-Only Content}

Supplemental material is available with the online version of the article.

Supplementary Tables and Figures. https://thejns.org/doi/ suppl/10.3171/2020.6.JNS20732.

\section{Previous Presentations}

A portion of the data in this study was presented as an oral presentation at the 2019 CNS Annual Meeting in San Francisco, CA, October 19-23, 2019.

\section{Correspondence}

Steven A. Toms: Rhode Island Hospital, Providence, RI. steven. toms@lifespan.org. 